\title{
Dietary determinants of ischaemic heart disease in health conscious individuals
}

\author{
Jim I Mann, Paul N Appleby, Timothy J Key, Margaret Thorogood
}

Department of Human Nutrition, University of Otago, PO Box 56, Dunedin, New Zealand J I Mann

\section{Imperial Cancer} Research Fund, Cancer Epidemiology Unit, University of Oxford, Oxford, UK P N Appleby

T J Key

London School of Hygiene and Tropical Medicine, University of London, London, UK

M Thorogood

Correspondence to: Professor Mann.

Accepted for publication 22 July 1997

\begin{abstract}
Objective-To investigate dietary determinants of ischaemic heart disease (IHD) in health conscious individuals to explain the reduced risk in vegetarians, and to examine the relation between IHD and body mass index (BMI) within the normal range.

Design-Prospective observation of vegetarians, semi-vegetarians, and meat eaters for whom baseline dietary data, reported weight and height information, social class, and smoking habits were recorded.

Subjects-10 802 men and women in the UK aged between 16 and 79, mean duration of follow up 13.3 years.

Main outcome measures-Death rate ratios for IHD and total mortality in relation to dietary and other characteristics recorded at recruitment (reference category death rate $=100$ ).

Results-IHD mortality was less than half that expected from the experience reported for all of England and Wales. An increase in mortality for IHD was observed with increasing intakes of total and saturated animal fat and dietary cholesterol-death rate ratios in the third tertile compared with the first tertile: 329 , 95\% confidence interval (CI) 150 to 721 ; $277,95 \%$ CI 125 to $613 ; 353,95 \%$ CI 157 to 796, respectively. No protective effects were observed for dietary fibre, fish or alcohol. Within the study, death rate ratios were increased among those in the upper half of the normal $B M I$ range (22.5 to $<25$ ) and those who were overweight $(B M I \geqslant 25)$ compared with those with BMI 20 to $<22.5$.

Conclusions-In these relatively health conscious individuals the deleterious effects of saturated animal fat and dietary cholesterol appear to be more important in the aetiology of IHD than the protective effect of dietary fibre. Reduced intakes of saturated animal fat and cholesterol may explain the lower rates of IHD among vegetarians compared with meat eaters. Increasing BMI within the normal range is associated with increased risk of IHD. The results have important public health implications.
\end{abstract}

(Heart 1997;78:450-455)

Keywords: ischaemic heart disease; diet; risk factors
Many foods and nutrients have been implicated as promotive or protective factors in the aetiology of ischaemic heart disease (IHD). Early interest centred around the atherogenic potential of saturated fatty acids and dietary cholesterol mainly derived from high fat dairy products, fatty meats, and eggs. ${ }^{1-3}$ More recent research has suggested that oils containing certain unsaturated fatty acids, fruits, vegetables, unrefined cereals, and fish might protect against IHD because of their antithrombotic properties or their antioxidant nutrient or dietary fibre (non-starch polysaccharide) content. ${ }^{4-10}$ It has been claimed that the beneficial effects of the protective foods might be more powerful than the deleterious effects of foods rich in saturated fatty acids. ${ }^{410}$ These observations have led to some uncertainty as to the most appropriate emphasis for dietary advice intended to reduce the risk of cardiovascular disease among populations and individuals at high risk of IHD.

We have recently confirmed reduced IHD death rates in vegetarians compared with meat eaters, ${ }^{11}{ }^{12}$ but vegetarian diets differ from those of meat eaters in many respects and published data have not established which aspects of the vegetarian diet are protective. We present information derived from a semiquantitative food frequency questionnaire completed by more than 11000 vegetarians and meat eaters at recruitment to a prospective study between 1980 and 1984. The study differs from previous prospective studies of diet and IHD in that the volunteers were individuals whose self selected diet $^{13}$ resembled, in nutrient content, current dietary recommendations ${ }^{14}$ rather than the relatively high saturated fat diet typical of most affluent societies. The findings may not only help to explain which attributes of a vegetarian diet protect against IHD but also which foods and nutrients are important in the aetiology of IHD in populations who modify their diets along the lines of present guidelines. Information on weight and height was also collected. An increased risk of IHD in obese subjects has been demonstrated in many studies. ${ }^{15}$ We report the change in IHD risk with increasing body mass index (BMI) within the normal range as very few volunteers were overweight.

\section{Subjects and methods}

RECRUITMENT

Recruitment is described in detail elsewhere. ${ }^{11}$ In brief, vegetarian participants were recruited through the Vegetarian Society of the United Kingdom and news media. The non-vegetarian controls were their friends and relatives. A 
Table 1 Number (percentage) of men and women with various lifestyle related characteristics and with pre-existing disease at the time of entry to the study

\begin{tabular}{|c|c|c|}
\hline & Men & Women \\
\hline Number of subjects & 4102 & 6700 \\
\hline Median age at entry (years) & 34 & 33 \\
\hline \multicolumn{3}{|l|}{ Diet group } \\
\hline Meat eater & $2147(52.3)$ & $2751(41.1)$ \\
\hline Semi-vegetarian & $387(9.4)$ & $962(14.4)$ \\
\hline Vegetarian/vegan & $1568(38.2)$ & 2987 (44.6) \\
\hline \multicolumn{3}{|l|}{ Smoking habits } \\
\hline Never smoked & $1787(43.6)$ & $4021(60.0)$ \\
\hline Ex-smoker & $1302(31.7)$ & $1588(23.7)$ \\
\hline \multicolumn{3}{|l|}{ Current smoker } \\
\hline$<10$ cigarettes/day & $531(12.9)$ & $487(7.3)$ \\
\hline$\geqslant 10$ cigarettes/day & $482(11.8)$ & $604(9.0)$ \\
\hline \multicolumn{3}{|l|}{ Body mass index $\left(\mathrm{kg} / \mathrm{m}^{2}\right)$} \\
\hline$<20$ & $592(14.4)$ & $1777(26.5)$ \\
\hline $20-$ & $1560(38.0)$ & 2804 (41.9) \\
\hline $22.5-$ & $1259(30.7)$ & $1425(21.3)$ \\
\hline$\geqslant 25$ & $691(16.8)$ & $694(10.4)$ \\
\hline \multicolumn{3}{|l|}{ Social class } \\
\hline I-II & $2190(53.4)$ & $3040(45.4)$ \\
\hline III-V & $1088(26.5)$ & $2017(30.1)$ \\
\hline Others & $824(20.1)$ & $1643(24.5)$ \\
\hline \multicolumn{3}{|l|}{ Pre-existing disease ${ }^{\star}$} \\
\hline No & $3832(93.4)$ & $6148(91.8)$ \\
\hline Yes & $270(6.6)$ & $552(8.2)$ \\
\hline
\end{tabular}

* Angina, heart disease, hypertension, diabetes or stroke.

semiquantitative food frequency questionnaire was completed and information gathered concerning smoking and exercise habits, social class, weight, and height at the time of recruitment to the study (September 1980 to January 1984, median year of recruitment 1981). Some characteristics of the participants are shown in table 1 .

\section{FOLLOW UP}

Flagging of each subject's medical records at the National Health Service Central Register enabled death certificates to be sent to the investigators following the death of participants. Underlying cause of death was coded by one of the investigators using the 9th Revision of the International Classification of Diseases. Coding was carried out without knowledge of the diet and lifestyle characteristics of the subject. We report an analysis of mortality based on all deaths up to 31 December 1995.

Table 2 Tertiles of the distribution of intake of total fat, saturated fat, and dietary cholesterol from animal foods

\begin{tabular}{|c|c|c|c|c|}
\hline & \multicolumn{2}{|l|}{ Men } & \multicolumn{2}{|l|}{ Women } \\
\hline & Tertiles & $\begin{array}{l}\text { Median intake } \\
\text { for each tertile }\end{array}$ & Tertiles & $\begin{array}{l}\text { Median intake } \\
\text { for each tertile }\end{array}$ \\
\hline Total animal fat & $\begin{array}{l}43.6 \text { and } \\
61.9 \mathrm{~g} / \mathrm{day}\end{array}$ & $\begin{array}{l}25.5 \\
52.4 \\
74.8\end{array}$ & $\begin{array}{l}37.0 \text { and } \\
55.1 \mathrm{~g} / \text { day }\end{array}$ & $\begin{array}{l}23.6 \\
45.2 \\
67.0\end{array}$ \\
\hline Saturated animal fat & $\begin{array}{l}23.9 \text { and } \\
34.0 \mathrm{~g} / \text { day }\end{array}$ & $\begin{array}{l}14.6 \\
27.4 \\
41.0\end{array}$ & $\begin{array}{l}20.6 \text { and } \\
31.0 \mathrm{~g} / \text { day }\end{array}$ & $\begin{array}{l}13.7 \\
26.3 \\
38.1\end{array}$ \\
\hline Dietary cholesterol & $\begin{array}{l}214.0 \text { and } \\
345.1 \mathrm{mg} / \text { day }\end{array}$ & $\begin{array}{l}155.6 \\
277.1 \\
431.4\end{array}$ & $\begin{array}{l}195.8 \text { and } \\
291.1 \mathrm{mg} / \text { day }\end{array}$ & $\begin{array}{l}137.7 \\
244.6 \\
378.1\end{array}$ \\
\hline Dietary fibre & $\begin{array}{l}22.4 \text { and } \\
32.5 \mathrm{~g} / \text { day }\end{array}$ & $\begin{array}{l}17.9 \\
27.3 \\
39.6\end{array}$ & $\begin{array}{l}20.9 \text { and } \\
29.1 \mathrm{~g} / \text { day }\end{array}$ & $\begin{array}{l}16.5 \\
24.7 \\
35.0\end{array}$ \\
\hline
\end{tabular}

DEFINITION OF DIETARY AND OTHER VARIABLES Data are presented for dietary variables for which there were (at the time the study was started) or are currently, hypotheses concerning promotion of or protection against IHD; and concerning which information was sought in the semiquantitative food frequency questionnaire. The validity of the questionnaire has been examined for estimated dietary fibre intake, but not for other nutrients. ${ }^{16}$ However, the food groups have been shown to be strongly related to serum cholesterol in this population. ${ }^{17}$ Vegetarianism was defined as never eating fish or meat or foods derived from animal products other than dairy foods and eggs. Individuals who ate meat occasionally but less than once a week or who ate fish but not meat were described as semi-vegetarians. For most variables the data are presented as recorded on the questionnaire, combining categories where appropriate to produce three intake categories. Those in the lowest intake category were regarded as the reference group. Subjects were also categorised into tertiles of the distribution of intake of total fat, saturated fat, and dietary cholesterol from animal foods (meat, eggs, milk, cheese) as well as for dietary fibre derived from cereal, fruit, and vegetable sources. Tertiles of the distribution of intake of these nutrients are shown in table 2 .

BMI was calculated from self reported weight and height. Socioeconomic status was classified on the basis of employment category. Leisure time physical activity was defined as high or low according to whether subjects participated in leisure time sport, keep fit, running or cycling for 15 minutes or more at least twice a week. Smoking habits were derived directly from data provided on the recruitment questionnaire.

\section{STATISTICAL METHODS}

Subjects under 16 years and those with diagnosed cancer (excluding non-melanoma skin cancer) at entry were excluded from the analyses as were those who failed to provide full information concerning smoking habits, height, weight, and employment category. The data presented are based on 10802 subjects (4102 men, 6700 women). Subjects were censored on reaching the age of 80 years. Personyears of observation and deaths in nine age groups (16-39 years and 5 year age groups 40-79 years) and three calendar periods (1980-84, 1985-89, 1990-95) were calculated using the person-years (PYRS) computer program. To describe the mortality of the cohort as a whole we also calculated standardised mortality ratios (SMRs) for men and women for all major causes of death using national mortality data for England and Wales; 95\% confidence intervals (CI) for the SMRs were calculated assuming that the observed number of deaths followed a Poisson distribution.

The associations of dietary and other factors with mortality within the cohort were investigated by Poisson regression using the GLIM-4 statistical package to calculate death rate ratios and their 95\% CI (for convenience we use a percentage scale, so that the reference category 
Table 3 Death rate ratio (95\% confidence interval) according to smoking habits, body mass index, and social class for participants without pre-existing disease at the time of recruitment

\begin{tabular}{|c|c|c|c|c|}
\hline & \multicolumn{2}{|c|}{ Ischaemic heart disease } & \multicolumn{2}{|c|}{ All causes of death } \\
\hline & $\begin{array}{l}\text { No of } \\
\text { deaths } \\
\text { (64) }\end{array}$ & Death rate ratio & $\begin{array}{l}\text { No of } \\
\text { deaths } \\
\text { (392) }\end{array}$ & Death rate ratios \\
\hline \multicolumn{5}{|l|}{ Smoking habits } \\
\hline Never smoked & 22 & 100 & 173 & 100 \\
\hline Ex-smoker & 25 & $131(73-237)$ & 131 & $112(88-141)$ \\
\hline \multicolumn{5}{|l|}{ Current smoker } \\
\hline$<10$ cigarettes/day & 5 & $128(47-344)$ & 34 & $125(86-181)$ \\
\hline$\geqslant 10$ cigarettes/day & 12 & $464(224-959)^{\star \star}$ & 54 & $241(176-329)^{\star \star}$ \\
\hline \multicolumn{5}{|l|}{ Body mass index $\left(\mathrm{kg} / \mathrm{m}^{2}\right)$} \\
\hline$<20$ & 8 & $158(61-409)$ & 81 & $141(106-189)^{\star}$ \\
\hline $20-$ & 9 & 100 & 107 & 100 \\
\hline $22.5-$ & 23 & $269(124-584)^{\star}$ & 117 & $135(103-176)^{\star}$ \\
\hline$\geqslant 25$ & 24 & $392(180-851)^{\star \star}$ & 87 & $155(116-207)^{\star \star}$ \\
\hline \multicolumn{5}{|l|}{ Social class } \\
\hline I-II & 19 & 100 & 128 & 100 \\
\hline III-V & 7 & $65(27-155)$ & 85 & $113(86-149)$ \\
\hline Others & 38 & $118(62-225)$ & 179 & $115(88-151)$ \\
\hline
\end{tabular}

Data adjusted for age, sex and for other variables listed.

Significance of difference from reference category: ${ }^{\star} 2 p<0.05,{ }^{\star} 2 \mathrm{p}<0.01$.

death rate ratio $=100)$. Because of the relatively small number of deaths for individual causes other than IHD, the data are presented for IHD (ICD codes 410-414) and total mortality. Death rate ratios were adjusted for age, sex, smoking habit, and social class. Twotailed $\mathrm{p}$ values were used to indicate death rate ratios significantly different from the reference value. Associations between mortality and the lifestyle related variables were further examined by testing for trend, for which one-tailed $p$ values are presented.

\section{Results}

A total of 525 deaths were observed in more than 143000 person-years at risk; overall mean duration of follow up 13.3 years. SMRs for all cause mortality in the entire cohort were 0.48 ( $95 \%$ CI 0.42 to 0.54$)$ for men, and 0.57 (0.50 to 0.64 ) for women. SMRs for IHD were 0.44 (0.35 to 0.56$)$ for men, and 0.46 (0.35 to 0.61$)$ for women, and for all malignant neoplasms 0.56 (0.44 to 0.69$)$ and 0.75 (0.63 to 0.89 ) for men and women, respectively.

Death rate ratios for those reporting preexisting diseases (angina, hypertension, heart disease, stroke or diabetes) at the time of diagnosis were 508 (353 to 731 ) and 211 (172 to 259) for IHD and total mortality, respectively. The main analyses relate only to individuals without reported disease at the time of recruitment. Death rate ratios in relation to smoking habits, BMI, and social class are shown in table 3. An increase in IHD and all cause mortality is apparent among those smoking 10 or more cigarettes per day compared with never smokers, and among those with $\mathrm{BMI} \geqslant 22.5 \mathrm{~kg} / \mathrm{m}^{2}$, compared with a BMI of 20 to $<22.5 \mathrm{~kg} / \mathrm{m}^{2}$. Total mortality was significantly higher in those with an initial $\mathrm{BMI}<20$, and a similar though not statistically significant trend is apparent for IHD mortality. There was no difference in death rate ratio between those defined as having high or low levels of leisure time physical activity (results not shown).
Death rate ratios for potentially deleterious or protective dietary factors are shown in table 4. A trend of increasing mortality for IHD was observed with increasing intake of total and saturated animal fat and dietary cholesterol. A similar trend was apparent for intake of eggs and cheese (other than cottage cheese). The death rate ratios were not appreciably altered when they were additionally adjusted for BMI. No significant trends were apparent between nutrient and food variables and total mortality, although those in the middle intake groups for eggs and milk had significantly lower death rate ratios than those in the lowest intake category. The highest intake of nuts (consumption on five or more occasions per week) was associated with a $23 \%$ reduction in all cause mortality which was not quite statistically significant (95\% confidence interval 58-101) when compared with the lowest intake (nuts eaten less than once per week).

Death rate ratios were also computed for individuals with pre-existing disease at the time of recruitment, and for all subjects. The trends for all subjects were similar to those presented for the group with no prior disease except that IHD mortality was significantly lower in the vegetarian/vegan group than in the meat eaters (death rate ratio $63 ; 95 \%$ CI 42-93). All cause mortality for all subjects was significantly lower in the middle and highest intakes of green vegetables $(62,95 \%$ CI $46-83$; and $74,95 \%$ CI 56-99) and among those consuming the highest intake of nuts (76, 95\% CI 60-97) compared with the lowest intakes of these foods.

\section{Discussion}

These findings relate to people who are mainly non-smokers, of high social class, and relatively lean. It is not surprising that all cause mortality is about half that expected for the population of England and Wales. Differences in dietary intake may also help to explain the reduction in mortality from IHD and malignant neoplasms in comparison with national rates; previously published data showed that both vegetarian and meat eating participants in the study ate diets with less saturated fat and more dietary fibre than the average for the British population. ${ }^{13}$ Thus, the study differs from other prospective studies that have examined diet and IHD in cohorts representative of the population at large or of particular employment groups. These results may therefore indicate which dietary factors are determinants of IHD mortality when populations comply with current dietary guidelines that emphasise the need to reduce the intake of saturated fatty acids and increase the intake of foods rich in dietary fibre. They also suggest reasons why vegetarians have lower IHD mortality rates than otherwise similar meat eaters.

The findings support the hypothesis that the nature and quantity of dietary fat and cholesterol are key determinants of IHD mortality. $^{23}$ A gradient of risk is apparent with increasing intake of total animal fat, saturated fat, and dietary cholesterol as well as some of the major food sources of these nutrients. 
Table 4 Death rate ratio (95\% confidence interval) for selected dietary factors, each adjusted for age, sex, smoking and social class for subjects with no evidence of pre-existing disease at the time of recruitment

\begin{tabular}{|c|c|c|c|c|c|c|}
\hline & \multicolumn{3}{|c|}{ Ischaemic heart disease } & \multicolumn{3}{|c|}{ All causes of death } \\
\hline & $\begin{array}{l}\text { No of } \\
\text { deaths } \\
\text { (64) }\end{array}$ & Death rate ratio & Trend & $\begin{array}{l}\text { No of } \\
\text { deaths } \\
\text { (392) }\end{array}$ & Death rate ratio & Trend \\
\hline \multicolumn{7}{|l|}{ Diet group } \\
\hline Meat eater & 32 & 100 & \multirow{3}{*}{ NS } & 170 & 100 & \multirow{3}{*}{ NS } \\
\hline Semi-vegetarian & 7 & $108(47-248)$ & & 45 & $102(73-143)$ & \\
\hline Vegetarian/vegan & 25 & $83(48-143)$ & & 177 & $102(82-127)$ & \\
\hline \multicolumn{7}{|l|}{ Meat } \\
\hline None eaten & 29 & 100 & \multirow{3}{*}{ NS } & 209 & 100 & \multirow{3}{*}{ NS } \\
\hline Less than daily & 18 & $153(84-279)$ & & 83 & $102(79-133)$ & \\
\hline Daily & 17 & $118(64-218)$ & & 94 & $101(79-130)$ & \\
\hline \multicolumn{7}{|l|}{ Eggs (per week) } \\
\hline$<1$ & 8 & 100 & \multirow{3}{*}{$\mathrm{p}<0.01$} & 89 & 100 & \multirow{3}{*}{ NS } \\
\hline $1-5$ & 33 & $128(59-279)$ & & 203 & $74(58-96)^{\star}$ & \\
\hline $6+$ & 23 & $268(119-602)^{\star}$ & & 89 & $92(68-123)$ & \\
\hline \multicolumn{7}{|l|}{ Milk (pints per day) } \\
\hline Less than half & 18 & 100 & \multirow{3}{*}{ NS } & 138 & 100 & \multirow{3}{*}{ NS } \\
\hline Half & 21 & $76(40-143)$ & & 139 & $70(55-88)^{\star \star}$ & \\
\hline More than half & 24 & $150(81-278)$ & & 106 & $87(68-113)$ & \\
\hline \multicolumn{7}{|l|}{ Cheese (excluding cottage) } \\
\hline$<$ once per week & 5 & 100 & & 55 & 100 & \\
\hline 1-4 times per week & 16 & $123(45-335)$ & $\mathrm{p}<0.01$ & 120 & $86(62-118)$ & NS \\
\hline$\geqslant 5$ times per week & 43 & $247(97-626)$ & & 208 & $102(76-137)$ & \\
\hline Total animal fat & & & & & & \\
\hline 1 st tertile & 9 & 100 & & 116 & 100 & \\
\hline 2nd tertile & 15 & $179(78-409)$ & $\mathrm{p}<0.01$ & 95 & $85(65-112)$ & NS \\
\hline 3rd tertile & 21 & $329(150-721)^{\star \star}$ & & 99 & $105(80-138)$ & \\
\hline Saturated animal fat & & & & & & \\
\hline 1st tertile & 9 & 100 & & 111 & 100 & \\
\hline 2nd tertile & 17 & $211(94-474)$ & $\mathrm{p}<0.01$ & 100 & $95(73-125)$ & NS \\
\hline 3rd tertile & 19 & $277(125-613)^{\star}$ & & 99 & $106(80-139)$ & \\
\hline Dietary cholesterol & & & & & & \\
\hline 1st tertile & 8 & 100 & & 116 & 100 & \\
\hline 2nd tertile & 15 & $181(77-429)$ & $\mathrm{p}<0.001$ & 90 & $74(56-97)^{\star}$ & NS \\
\hline 3rd tertile & 22 & $353(157-796)^{\star \star}$ & & 104 & $102(78-134)$ & \\
\hline Fish & & & & & & \\
\hline Never eaten & 26 & 100 & & 184 & 100 & \\
\hline$<$ once per week & 13 & $121(62-238)$ & NS & 82 & $97(74-126)$ & NS \\
\hline$\geqslant$ once per week & 25 & $123(70-217)$ & & 123 & $96(76-121)$ & \\
\hline Green vegetables & & & & & & \\
\hline$<$ once per week & 4 & 100 & & 39 & 100 & \\
\hline $1-4$ times per week & 29 & $119(42-340)$ & NS & 171 & $74(52-105)$ & NS \\
\hline$\geqslant 5$ times per week & 30 & $134(47-384)$ & & 176 & $89(63-126)$ & \\
\hline Carrots & & & & & & \\
\hline$<$ once per week & 14 & 100 & & 60 & 100 & \\
\hline 1-4 times per week & 29 & $57(30-108)$ & NS & 226 & $107(80-142)$ & NS \\
\hline$\geqslant 5$ times per week & 18 & $76(37-157)$ & & 96 & $99(72-138)$ & \\
\hline Fresh or dried fruit & & & & & & \\
\hline$<5$ times per week & 17 & 100 & & 106 & 100 & \\
\hline 5-9 times per week & 29 & $107(58-196)$ & NS & 151 & $89(69-114)$ & NS \\
\hline$\geqslant 10$ times per week & 17 & $89(44-180)$ & & 128 & $97(74-127)$ & \\
\hline Nuts & & & & & & \\
\hline$<$ once per week & 30 & 100 & & 188 & 100 & \\
\hline 1-4 times per week & 21 & $119(68-210)$ & NS & 123 & $99(79-125)$ & NS \\
\hline$\geqslant 5$ times per week & 13 & $87(45-168)$ & & 72 & $77(58-101)$ & \\
\hline Dietary fibre & & & & & & \\
\hline 1st tertile & 7 & 100 & & 82 & 100 & \\
\hline 2nd tertile & 14 & $192(77-479)$ & NS & 88 & $101(75-137)$ & NS \\
\hline 3rd tertile & 17 & $225(92-553)$ & & 93 & $98(73-133)$ & \\
\hline Alcohol & & & & & & \\
\hline 0 or $<1$ unit per week & 24 & 100 & & 158 & 100 & \\
\hline $1-7$ units per week & 25 & $131(74-234)$ & NS & 122 & $88(69-113)$ & NS \\
\hline$>7$ units per week & 15 & $102(51-203)$ & & 108 & $104(79-135)$ & \\
\hline
\end{tabular}

$\star 2 \mathrm{p}<0.05 ;{ }^{\star} \star 2 \mathrm{p}<0.01$.

Numbers of deaths may not total 64 or 392 because values of the dietary factors were unknown for some subjects.

Further indirect support for a key role of dietary saturated fat and cholesterol in promoting IHD comes from the difference in serum cholesterol between vegetarians and meat eaters; we and others have reported differences of between 0.4 and $0.6 \mathrm{mmol} / 1 .^{18-20}$ Law et al estimated that a $0.6 \mathrm{mmol} / 1$ difference in total serum cholesterol would cause a $27 \%$ difference in IHD mortality and a $10 \%$ difference in all cause mortality, ${ }^{21}$ predictions that are close to those observed in a meta-analysis including our own and four other studies of vegetarians. ${ }^{12}$ Serum cholesterol differences of this magnitude would be predicted on the basis of the 
difference in intake of saturated fat and cholesterol between vegetarians and non-vegetarians. ${ }^{1322}$

Other recent studies have suggested that the deleterious effect of saturated fat and cholesterol is less important than the protective effects of dietary fibre and linolenic acid. ${ }^{410}$ However, in the present study there was a wide range of dietary fat intakes, resulting from the inclusion of vegans, vegetarians, semi-vegetarians, and meat eaters. Most other cohort studies have involved more homogeneous populations with a relatively narrow range of fat intakes. It is impossible to identify even strong disease associations if there is little variation in a dietary variable in the study population. Conversely, the absence of an effect of dietary fibre in our data could be due to the fact that our cohort had average intakes above that observed in other studies ${ }^{4}$ and that a gradient of risk is no longer apparent with intakes in this higher range.

We were not able to examine the potentially protective effects of antioxidant nutrients or of long chain unsaturated fatty acids. When the study started there were no clear hypotheses concerning effects of these nutrients so the questionnaire did not include details of relevant foods. We were unable to detect a protective effect of either fish intake ${ }^{7}$ or alcohol, ${ }^{23}$ which have been reported in several other studies. The most likely explanation is a relatively narrow spread of intakes. The cohort as a whole had a relatively low intake of alcohol and fish. Another possible explanation for the failure to demonstrate a protective effect of alcohol may lie in the fact that alcohol primarily exerts its cardioprotective effect in those with moderately raised LDL cholesterol. $^{24}$ Vegetarianism was associated with a $17 \%$ reduction in mortality from IHD. This was not statistically significant, but is consistent with the $25 \%$ reduction observed in the recent meta-analysis of this and four other studies. ${ }^{12}$

There are no consistent and significant trends between dietary variables and all cause mortality. It is difficult to be certain whether the lower all cause mortality among those in the middle intake groups for eggs and milk is of biological significance or simply a chance finding as there were no prior hypotheses regarding intakes of these foods and total mortality. Perhaps of more interest is the reduced mortality in those consuming nuts five times or more per week compared with less than once per week, a finding that did not quite achieve statistical significance in those without pre-existing disease (death rate ratio $77 ; 95 \%$ CI 58-101), but did achieve statistical significance when the data were examined for all subjects. Nuts are good sources of vitamin $\mathrm{E}$, other antioxidant nutrients, and linoleic acid and appeared to be responsible for some of the reduced IHD mortality among Seventh-day Adventist vegetarians. $^{25}$

The semiquantitative food frequency questionnaire was a relatively crude instrument, having been designed before the development of the more sophisticated food frequency questionnaires currently employed in large scale epidemiological studies. However, we are confident of its ability to provide reasonable estimates of dietary fat, cholesterol, and fibre. Special attention was given to the food sources of these nutrients as they were of particular interest when the study was planned. The associations demonstrated remained after adjusting for major potential confounding factors (age, sex, smoking, social class, and BMI), and restricting the data to individuals with no previous cardiovascular disease or diabetes. Thus, reported diet is unaffected by dietary advice or self selected food choices intended to treat various diseases and this potentially important source of bias is thereby removed.

The data on self reported height and weight are important as they relate to a population with a reduced prevalence of overweight and obesity compared with the general population in Britain. A BMI $<20$ is associated with a significantly increased mortality from non-IHD causes, an observation made in many other studies $^{26}$ and perhaps due to disease present but not yet diagnosed at the time of recruitment. The increase in IHD mortality in this group was not statistically significant. On the other hand, IHD mortality showed a nearly threefold increase in the high normal range $\left(22.5\right.$ to $<25 \mathrm{~kg} / \mathrm{m}^{2}$ ) compared with the low normal range $\left(20\right.$ to $\left.<22.5 \mathrm{~kg} / \mathrm{m}^{2}\right)$, the risk increasing to fourfold in those with BMIs in the overweight or obese range $\left(\geqslant 25 \mathrm{~kg} / \mathrm{m}^{2}\right)$. The low prevalence of obesity precluded more detailed analyses among the obese (BMI $\geqslant 30 \mathrm{~kg} / \mathrm{m}^{2}$ ). Although the gradient of risk within the normal range is based on only nine deaths from IHD in the reference group, the increased mortality in the high normal range is a phenomenon previously documented ${ }^{27}{ }^{28}$ but not widely appreciated and with important public health implications. Non-IHD mortality was also higher in the overweight category, though not to the same extent as for IHD.

In summary we conclude that dietary saturated animal fat and cholesterol are important in the aetiology of IHD. These factors, rather than simply meat, ${ }^{29}$ appear to explain the higher IHD rates reported in meat eaters compared with vegetarians and are of particular relevance in a population consuming a diet lower in saturated fatty acids and higher in dietary fibre than that currently consumed in most relatively affluent western societies. With the possible exception of nuts, there was little evidence for an important role for potentially protective foods; however, it is not clear whether this was due to inadequacies of the instrument for measuring dietary intake or whether protective foods and nutrients play a less important role in populations or groups who have already opted for a diet that is high in vegetables, fruits, and cereals.

1 Keys A. Seven countries: a multivariate analysis of death and coronary heart disease. Cambridge: Harvard University Press, 1980

2 Stamler J, Dyer AR, Shekelle RB, Neaton J, Stamler R. Relationship of baseline major risk factors to coronary and all-cause mortality, and to longevity: findings from 
long-term follow-up of Chicago cohorts. Cardiology 1993; 82:191-222.

3 Keys A, Menotti A, Karvonen MJ, Aravanis C, Blackburn $\mathrm{H}$, Buzina $\mathrm{R}$, et al. The diet and 15-year death rate in the Seven Countries Study. Am f Epidemiol 1986;124:903-15.

4 Ascherio A, Rimm EB, Giovannucci EL, Spiegelman D, Stampfer M, Willett WC. Dietary fat and risk of coronary heart disease in men: cohort follow up study in the United States. BMf 1996;313:84-90.

5 Rimm EB, Stampfer MJ, Ascherio A, Giovannucci D, Colditz GA, Willett WC. Vitamin E consumption and the risk of coronary heart disease in men. $N$ Engl f Med 1993;328: 1450-6.

6 Hertog MGL, Kromhout D, Aravanis C, Blackburn H, Buzina R, Fidanza F, et al. Flavonoid intake and long-term risk of coronary heart disease and cancer in the Seven Countries Study. Arch Intern Med 1995;155:381-6.

7 Kromhout D, Bosschieter EB, Coulander C deL. The inverse relation between fish consumption and 20 -year mortality from coronary heart disease. N Engl f Med 1985; 312:1205-9.

8 Nyyssönen K, Parviainen MT, Salonen R, Tuomilehto J, Salonen JT. Vitamin C deficiency and risk of myocardial infarction: prospective population study of men from eastern Finland. BMF 1997;314:634-8.

9 Kristenson M, Ziedén B, Kucinskienë Z, Schafer Elinder L, Bergdahl B, Elwing B, et al. Antioxidant state and mortality from coronary heart disease in Lithuanian and Swedish men: concomitant cross sectional study of men aged 50 . BMF 1997;314:629-33.

10 Pietinen P, Rimm EB, Korhonen P, Hartman AM, Willett WC, Albanes D, et al. The alpha-tocopherol, beta-carotene cancer prevention study. Intake of dietary fibre and risk of coronary heart disease in a cohort of Finnish men. Circulation 1996;94:2720-7.

11 Thorogood M, Mann J, Appleby P, McPherson K. Risk of death from cancer and ischaemic heart disease in meat and death from cancer and ischaemic heart disea

12 Key TJA, Fraser GE, Thorogood M, Appleby P,N, Beral V, Reeves G, et al. A collaborative analysis of mortality in five population studies. Am $\mathcal{F}$ Clin Nutr. [In press.]

13 Thorogood M, Roe L, McPherson K, Mann J. Dietary intake and plasma lipid levels: lessons from a study of the diet of health conscious groups. BMf 1990;300:1297-301.

14 Department of Health. Dietary reference values for food energy and nutrients for the United Kingdom. Report on health and social subjects 41. London: HMSO, 1991.

15 Bengtsson C, Björkelund L, Lapidus L, Lissner L Association of serum lipid concentrations and obesity with mortality in women: 20 year follow up of participants in prospective population study in Gothenburg, Sweden. BMF 1993;307:1385-8.
16 Gear JSS, Ware AC, Fursdon P, Mann JI, Nolan DJ, Brodribb A, Vessey MP. Symptomless diverticular disease and intake of dietary fibre. Lancet 1979;i:511-14.

17 Appleby PN, Thorogood M, McPherson K, Mann J. Associations between plasma lipid concentrations and dietary, lifestyle and physical factors in the Oxford Vegetarian Study. F Hum Nutr Dietet 1995;8:305-14.

18 Thorogood M, Carter R, Benfield L, McPherson K, Mann JI. Plasma lipids and lipoprotein cholesterol concentrations in people with different diets in Britain. BM7 1987;295. 351-3.

19 Burr ML, Bates CJ, Fehily AM, St Leger AS. Plasma cholesterol and blood pressure in vegetarians. F Human Nutr 1981;35:437-41.

20 West RO, Hayes OB. Diet and serum cholesterol levels. A comparison between vegetarians and nonvegetarians in a Seventh-day Adventist group. Am 7 Clin Nutr 1968;21: 853-62.

21 Law MR, Wald NJ, Wu T, Hackshaw A, Bailey A. Systematic underestimation of association between serum cholesterol concentration and ischaemic heart disease in observational studies: data from the BUPA study. BMF 1994;308:363-6.

22 Clarke R, Frost C, Collins R, Appleby P, Peto R. Dietary lipids and blood cholesterol: quantitative meta-analysis of metabolic ward studies. BMF 1997;314:112-17.

23 Jackson R, Scragg R, Beaglehole R. Alcohol consumption and risk of coronary heart disease. BMF 1991;303:521-2.

24 Hein HO, Suadicani P, Gyntelberg F. Alcohol consumption, serum low density lipoprotein cholesterol concentration, and risk of ischaemic heart disease: six year follow up in the Copenhagen male study. BMf 1996;312:736-41.

25 Fraser GE, Sabaté J, Beeson WL, Strahan M. A possible protective effect of nut consumption on risk of coronary heart disease. Arch Intern Med 1992;152:1416-24.

26 Seidell JC, Verschuren WM, van Leer EM, Kromhout D. Overweight, underweight, and mortality. A prospective study of 48,287 men and women. Arch Intern Med 1996;156:958-63.

27 Linsted K, Tonstad S, Kuzma JW. Body mass index and patterns of mortality among Seventh-day Adventists. Int $\mathcal{F}$ Obesity 1991;15:397-406.

28 Manson JE, Willett WC, Stampfer MJ, Colditz GA, Hunter DJ, Hankinson SE, Hennekens CH, Speizer FE. Body weight and mortality among women. $N$ Engl $f$ Med 1995;333:677-85.

29 Snowdon DA, Phillips RL, Fraser GE. Meat consumption and fatal ischemic heart disease. Prev Med 1984;13:490500. 